\title{
Öğretmenlerin Sağlık Okuryazarlığı Düzeylerinin Yükseltilmesi Neden Önemlidir?
}

\author{
Ayşe DOST*, Elif ÜNER**
}

\begin{abstract}
$\ddot{0} \mathbf{z}$
Sağlık okuryazarlığı, sağlığın korunması ve geliştirilmesi için gerekli olan bilgiye ulaşma, anlama ve bu bilgiyi kullanma konusunda sahip olunan bilişsel ve sosyal bir beceridir. Bilim dünyası tarafından geliştirilen bilgilerin, toplum için anlaşılır bir dil ve ulaşılabilir araçlarla iletilmesi ve bu bilgilerle uygun davranış geliştirmesi stratejik amaçlardan biridir. Ottowa Birinci Sağlığın Geliştirmesi Konferansı'nda, sağlı̆̆ı geliştirme çalışmalarının yalnızca sağlık sektörünün çabası ile başarılmasının mümkün olmadı̆̆ı diğer sektörlerinde bu konuda sorumluluk almaları gerektiği belirtilmiştir. Sağllk sektörüne eşlik etmesi beklenen eğitim sektörünün ana kahramanı olan öğretmenlerin, sağlık okuryazarlı̆̆ı düzeylerinin yükseltilmesi, kendileri ve toplum açısından oldukça önemlidir. Bu kapsamda öğretmenlerin sağlık okuryazarlığı düzeyini yükseltmeye yönelik eğitimlerin verilmesi önem arz etmektedir. Bu derlemede, öğretmenlerin sağllk okuryazarlığı düzeylerinin yükseltilmesinin önemine ilişkin bilgi vermek ve literatür taraması yapılarak öğretmenlerin sağlık okuryazarlığı düzeylerinin değerlendirilmesi amaçlanmıştır.
\end{abstract}

Anahtar kelimeler: Öğretmen, sağlık okuryazarlığı, sağllğı geliştirme.

\section{Why is it Important to Raise Teachers' Health Literacy Levels?}

\footnotetext{
Abstract

Health literacy is a cognitive and social ability to access, understand and use the information necessary for the protection and development of health. It is one of the strategic objectives to

\section{Derleme Makale (Review Article)}

Geliş / Received: 07.07.2020 \& Kabul / Accepted: 27.11.2020

DOI: https://doi.org/10.38079/iqusabder.766017

* Öğr. Gör., İstanbul Medipol Üniversitesi, Sağlık Bilimleri Fakültesi, Hemşirelik Bölümü, İstanbul, Türkiye, E-posta: adost@medipol.edu.tr ORCID https://orcid.org/o000-0002-46517254

** Doktora Öğrencisi, Marmara Üniversitesi, Halk Sağlı̆̆ Anabilim Dalı, İstanbul, Türkiye, E-posta: uner.elifnaz@gmail.com ORCID https://orcid.org/o00o-0003-2546-7048
} 
transmit the information developed by the scientific world in a language understandable and accessible to society and to develop appropriate behavior with this information. At the Ottowa First Health Promotion Conference, it was stated that health promotion activities cannot be achieved only with the efforts of the health sector, but they should take responsibility in this field in other sectors. Increasing the health literacy levels of teachers, who are the main hero of the education sector, which is expected to accompany the health sector, is very important for them and society. In this context, it is important to provide training to increase the level of health literacy of teachers. In this review, it is aimed to give information about the importance of increasing the health literacy levels of teachers and to evaluate the health literacy levels of teachers as a result of the literature review.

Keywords: Teacher, health literacy, health promotion.

\section{Giriş}

Dünya Sağlı Örgütü (DSÖ)'nün yapmış olduğu tanıma göre sağlı okuryazarlığı; sağlığın korunması ve geliştirilmesi için gerekli olan bilgiye ulaşma, anlama ve bu bilgiyi kullanma konusunda sahip olunan bilişsel ve sosyal bir beceri ve motivasyon düzeyidir ${ }^{1}$. Amerikan Tıp Birliği sağlık okuryazarlığını, sağlıklı yaşamın sürdürülmesi için gerekli olan temel okuma ve işlemsel görevleri yerine getirme kapasitesini içine alan becerilerin "takımyıldızı" olarak tanımlanmaktadır².

Sağlık okuryazarlı̆̆ı sosyodemografik özelliklerden etkilendiği kadar bilişsel ve sosyal yeteneklerden de etkilenmektedir ve bireyin sağlı bakımına ulaşmasını, kullanmasını ve bakım sağlayıcılarla etkileşim içinde olma yeteneğini etkilemektedir33.4. Sağlık okuryazarlığı yetersiz düzeyde olan bireylerin, koruyucu sağllk hizmetlerine daha az başvurdukları ve erken teşhis edilebilecek sağlık durumları için tarama sıklı̆̆ında azalma yaşadıkları ileri sürülmektedir5. Amerika Birleşik Devletleri (ABD) ve Avrupa Birliği'nde yapılmış çalışmalar incelendiğinde gelişmiş ülkelerde bile toplumun yaklaşık \%50'sinin yetersiz sağlık okuryazarlığı düzeyinde olduğunu göstermekte iken ülkemizde yapılmış kimi çalışmalarda, toplumun yaklaşık \%70’inin yetersiz sağllk okuryazarlığı düzeyine sahip olduğunu göstermektedir6́.

Ottowa Birinci Sağllğın Geliştirmesi Konferansı'nda (1986), evrensel boyutta sağllğıın geliştirilmesi tartışılırken, sağlığı geliştirme çalışmalarının yalnızca sağlık sektörünün sorumluluğunda olmadı̆̆ı, multisektörel bir çalışma ortamına ihtiyaç olduğu 
belirtilmiştir. Ottowa Şartnamesi'nin 30. yılında düzenlenen Şangay 9. Küresel Sağlığın Geliştirilmesi Konferansı'nda (2016) ise, ana temalardan biri olarak 'sağlık okuryazarlığına' yer verilmiştir7. Bu kapsamda bilim dünyası tarafından geliştirilen bilgilerin toplum için anlaşılır bir dil ve ulaşılabilir araçlarla iletilmesi, toplumun bu bilgilere ulaşabilmesi, anlaması, yorumlaması ve bu bilgilerle uygun davranış geliştirmesi stratejik amaçlardan biridir. Bu noktada sağlık sektörüne eşlik etmesi beklenen eğitim sektörünün ana kahramanı olan öğretmenlerin, sağlık okuryazarlığı düzeylerinin artırılması kendileri ve toplum açısından oldukça önemlidir.

Öğretmenler okul çağındaki çocuklar ile sağlık sistemi, eğitim sistemi ve sağlık konuları arasında birleştirici işlev görmektedir ${ }^{8}$ Öğretmenlerin sağlık eğitimi sürecindeki rolü çok önemlidir, bu nedenle sağlık okuryazarlığı ve sağlık yeterlilikleri okulda sağlık eğitimini gerçekleştiren ana bileşenlerdir. $\mathrm{Bu}$ derlemede, öğretmenlerin sağlık okuryazarlığı düzeylerinin artırılmasının önemine ilişkin bilgi vermek ve literatür taraması yapılarak sonucunda öğretmenlerin sağlık okuryazarlığı düzeylerinin değerlendirilmesi amaçlanmıştır.

\section{Öğretmen Sağlık Okuryazarlığı}

Öğretmen sağlık okuryazarlığı “öğretmenlerin temel sağlık bilgi ve hizmetlerini elde etme, yorumlama ve anlama kapasitesi, bu tür bilgi ve hizmetleri okul öğrencileri tarafından sağlık kavramı ve becerilerinin öğrenilmesini geliştirecek şekilde kullanma yetkisi” olarak tanımlanmaktadır. Öğretmen sağlı okuryazarlığı, öğrenci sağlık okuryazarlığının karşılığı olarak görülebilmektedir. Öğrenciler sınıfta sağlık bilgilerinin tüketicisi iken, öğretmenler sağlık bilgilerinin sağlayıcısıdır`.

Sağlayıcı (öğretmen) sağlık okuryazarlığı, tüketici (öğrenci) sağlık okuryazarlığı kadar önemlidir. Çocuk ve ergen sağlı̆̆ının geliştirilmesinde sağlayıcı-tüketici ilişkisinin her iki ucunun en üst düzeye çıkarılması, öğretmenlerin ve diğer sağlık profesyonellerinin hazırlanmasının yanı sıra okul sağlığı eğitiminin geliştirilmesine yardımcı olmalıdır ${ }^{10}$.

Amerikan Sağlık Eğitimi Derneği, 1996 yılında kabul ettiği kararda, öğretmenler için sağlık eğitiminde önerilen yeterlilikleri özetlemiştir. $\mathrm{Bu}$ yeterlilikler sağlık okuryazarlığında bir eğitimcinin taşıması gereken özellikleri olarak kabul edilmektedir ${ }^{11}$ :

- Ulusal Sağlık Eğitim Standartlarını mevcut müfredatlara uyarlamak, 
- Toplum sağlığı, tüketici sağlığı, çevre sağlığı, aile hayatı, zihinsel ve duygusal sağlık, yaralanmaların önlenmesi ve güvenliği, beslenme, kişisel sağlık, hastalıkların önlenmesi ve kontrolü ve alkol-tütün ilaçlarının önlenmesi konularında temel bilgilere sahip olmak,

- Kapsamlı bir okul sağlığı programının bir bileşeni olarak okul sağlığı eğitiminin rolü konusunda farkındalık göstermek,

- Sağlık kavramlarının öğretimini müfredata entegre etmek,

- Yaşa uygun çocuk gelişimi ilkelerini sağlık eğitimi metodolojisine uyarlamak,

- Sağlık davranışı ile ilgili karar verme becerilerinin etkili bir şekilde nasıl öğretileceğini kavramak,

- Sağlık eğitimi için kaynakları toplamak ve değerlendirmek,

- Sağlık konularını ve politikalarını ele almak için okuldaki ve toplumdaki çok disiplinli ekiplerle iş birliği içinde kültür ve kişisel inançların oynadığı rolü anlamada aileleri ve toplulukları ortak olarak kullanmak.

Sağlığın geliştirilmesinde, halk sağlığı kapsamında geleneksel erken çocukluk hastalıklarına yönelik önemli ilerlemeler kaydedilmiş olsa da okul çağındaki çocukların ve ergenlerin sağlık durumunun iyileştirilmesi için büyük zorluklar devam etmektedir. Giderek artan olumsuz çocuk-ergen yaşam tarzı davranışları, anksiyete, depresyon, stres, zayıf benlik saygısı ve yabancılaşmayı tetikleyen sosyal çevre koşullarıyla şiddetlenen ciddi sağlık sorunları ile karşı karşıyadır. Riskli davranışlar, gençlerde endişe verici derecede artan sağlık sorunlarına neden olmaktadır. Okullar, sağlık okuryazarlığı olmayan ve önemli sağlık ihtiyaçları olan öğrencilerin ihtiyaçlarını ele alma zorluğu ile karşı karşıyadırı10,12.

Çocuk-ergen sağlığını koruma ve geliştirmeye yönelik planlanan önemlerin ve girişimlerin alınması gelecekte sağlıklı toplumun temelinin atılmasında büyük önem taşımaktadır. Simonds, çocukların yalnızca tarih, fizik gibi alanlarda değil, sağlık alanında da okur-yazar olmaları gerektiğini söyleyerek okullarda sağlık eğitiminin önemini belirtmektediri³. Okul sağlığı hizmetlerinin çok disiplinli ekip yaklaşımı ile yürütülmesi gereklidir ${ }^{14}$. Ancak ülkemizde ne yazık ki kamuya ait okullarda okul sağlı̆̆ hizmetlerini yürütecek revir ya da okul sağlığı birimleri yoktur ya da sağlık ekibi üyesi 
istihdam edilmemektedir. Yürütülen çalışmalar sonucunda; ülkemizde yatılı eğitim kurumlarında da sürekli sağlık personeli ve okul sağlı̆̆ hizmetlerinin olmadığı saptanmış, bu açıdan öğrencilerin ve okul personellerinin sorun yaşadığı belirtilmiştir ${ }^{15-}$ 17. Arabacı ise çalışmasında; okulda revir ortamının ve sağlık personellerinin bulunmasının olumlu sağlık davranışları geliştirilmesinde ve sağlıklı çevre oluşturulmasında katkı sağlayacağını vurgulamıştır ${ }^{18}$. Bu nedenle okul sağlık hizmetlerinin yürütülmesinde sağlık çalışanları ile öğretmenler ile iş birliği yapılarak öğretmenlerin sağlık okuryazarlığı düzeylerinin artırılması ve danışmanlık, eğitim ve gözlem gibi etkinlikleri ile öğrencilerin sağlığının geliştirilmesinde rol oynaması önem arz etmektedir.

Öğretmenlerin sağlık okuryazarlığı düzeyleri, çalıştıkları ortam nedeni ile hem kendileri hem de topluma kazandırdıkları öğrencileri açısından önem teşkil etmektedir. Öğretmen adaylarının sağlık okuryazarlığı düzeyinin sağlık okuryazarlığının geliştirilmesi temel alan ve benzeri konular üzerine tartışan araştırma eksikliği vardır ${ }^{19}$. Öğretmenler çoğunlukla çocuklarla ve gençlerle çalışmaktadırlar. Bilindiği gibi, gençlerin davranışları ve yaşam biçimleri, çeşitli yaş dönemlerinde büyüme ve gelişme sürecinde önemli ölçüde değişmektedir. Örneğin, ergenlik sigara, alkol ve uyuşturucu kullanımı gibi yaşamın olumsuz yönlerinin ortaya çıkabileceği çok riskli bir yaşam dönemidir. Öğretmen sadece özel bilgi (örneğin sağlık bilgisi vb.) sağlayıcısı değil, aynı zamanda sağlığa yönelik davranış ve tutum örneğidir. Eğitim sürecinde öğretmen öğrencilere sağlık bilgilerini iletmeli, somut bir kişi veya grubun davranış değişikliklerine neden olmaya çalışmalı ve davranışın sağlık için olumlu yönde değişmesi için koşulları oluşturmalıdır8.

Bu nedenle, öğretmenlerin işlevlerinden biri, öğrencilere sürekli sağlık okuryazarlığının iyileştirilmesi için gerekli olan yetenek ve becerileri kazanma olanakları oluşturmak amacıyla gerekli ve nitelikli sağlık okuryazarlığı araçlarını sağlamaktır²0. Bu açıdan bakıldığında, öğretmenlerin sağlık okuryazarlığı düzeyinin belirlenmesiyle; eğitim sisteminin tüm seviyelerinde sağlık okuryazarlığını geliştirmeye, sağlık açısından riskli davranışları azaltmaya, sağlığın korunmasını bilincini geliştirmeye yönelik çalışmalar oluşturulmalıdır. Öğretmenlerin öğrencilerine, temel düzeyde sağlık bilgisini ve sağlıklı bir yaşam için sağlık risklerinden nasıl korunabileceğini öğretmesi gereklidir².

Öğretmen adaylarının üniversite yıllarında katılmış oldukları çalışmalar sonucunda, sağlık yeterliliğinin gelişimine açık oldukları, ancak mezuniyet sonrası çalışma ortamının 
sağlık okuryazarlığının iyileştirilmesine, sağlık yeterliliğin oluşumuna katkısının zayıf olduğu görülmüştür9 .

Litvanya'da yapılan bir araştırmada; öğretmenlerin sağlık okuryazarlığının oldukça düşük olduğu, sağlıklı yaşam alışkanlıklarının nasıl oluşturulacağı, sağlıklı bir yaşamın nasıl yaşanacağı hakkında somut bilgi eksikliği olduğu bildirilmiştir. Bu araştırmada öğretmenlerin \%28,8'i iyi/yeterli sağlık okuryazarlığına, \%42’si yetersiz sağlık okuryazarlığına, \%29,2'sinin ise sorunlu sağlık okuryazarlığına sahip olduğu tespit edilmiştir ${ }^{21}$. Hill ve Hollis tarafından yapılan bir çalışmada ise, öğretmenlerin ilköğretim öğrencilerinin sağlık problemlerine her gün bir saat ayırdıkları saptanmıştır ${ }^{14}$.

Ülkemizde de öğretmenlerin sağlık okuryazarlığı ile ilgili literatür oldukça sınırlı olmakla birlikte yapılan çalışmalarda öğretmenlerin büyük çoğunluğunun sağlık okuryazarlığı düzeyleri düşük bulunmuştur. İlköğretim öğretmenlerinin sağlık okuryazarlı̆̆ı düzeyini belirlemek amacıyla 2014 yılında yapılan bir çalışmada, öğretmenlerin sadece \%26,2'sinin yeterli sağlık okuryazarlığı (SOY) düzeyine sahip olduğu belirlenmiştir. Çalışmada yeterli SOY düzeyleri 25-34 yaş grubunda diğer yaş gruplarına göre, kadınlarda erkeklere göre daha yüksek olduğu bulunmuştur. Diğer meslek gruplarına göre eşinin sağlık personeli olduğunu belirtenlerde yeterli SOY düzeyleri daha yüksek olduğu tespit edilmiştir. Kişilerin sağlıklı yaşam konularına ilgi duymasına göre yeterli SOY düzeyleri anlamlı farklılık göstermektedir. Medyada sağlıklı yaşam ile ilgili konularla ilgilendiğini söyleyenlerde yeterli SOY düzeyine sahip olma sıklığı daha yüksektir². Kesitsel nitelikteki bir diğer araştırmada ise; Malatya ilinde çalışan 875 öğretmenin \%49,6'sı yetersiz/sorunlu, \%50,4'ü yeterli veya mükemmel SOY kategorisinde tespit edilmiştir. İlköğretim öğretmenlerinin sağlık okuryazarlığı düzeyleri sınırlıdır. İlköğretim öğretmenlerinde hastalık farkındalı̆̆ı ve kontrolüne göre yeterli sağlık okuryazarlığı düzeyleri düşüktür ${ }^{14}$. Avrupa Sağlık Okuryazarlığı araştırmasında eğitim düzeyi yükseldikçe sağlık okuryazarlığı düzeyinin de yükseldiği tespit edilmesine rağmen toplumun yüksek eğitim seviyesine sahip bireylerinden olan öğretmenlerde sağlık okuryazarlığı düzeyinin yeterli olmadığı, yaklaşık yarısının yetersiz veya sorunlu sağlık okuryazarlığı düzeyinde olduğu görülmektedir ${ }^{22}$. 


\section{Sonuç ve Öneriler}

Eğitimcilerde sağlık okuryazarlığı düzeyinin sınırlı olması genel toplumda sınırlı sağlık okuryazarlığı düzeyinin daha yüksek olabileceğini düşündürmektedir. Eğitimcilerde sınırlı sağlık okuryazarlığı düzeyi eğitim sistemimizin sağlı eğitimi programları açısından zayıf olduğunu göstermektedir. Sağlık sektörü, eğitim sektörü, üniversiteler, sivil toplum örgütleri ve medyanın içinde yer aldığı multisektöriyel çabalar oluşturulmalıdır. Bu bilgilerden yola çıkarak;

- Ülkedeki tüm öğretmenlerin sağlık okuryazarlığg düzeylerinin belirlenmesi, gerekli eylem planları hazırlanarak uygulamaya konulması gerekmektedir.

- Öğretmenlerin gençliğin karşılaştığı sorunları, temel önleme ilkelerini ve etkili birinci basamak sağlık ve sağlı̆̆ı geliştirme programlarının uygulanmasına yönelik temel kavramları anlamalarına yardımcı olabilecek koruyucu ve hizmet içi profesyonel öğretmen hazırlığına (temel ve ikincil) ihtiyaç vardır.

- Topluma birey kazandıran öğretmenler başta olmak üzere birçok meslek grubuna sağlık okuryazarlığı bilinci kazandırılmalı, eğitimler verilmeli ve toplumun her kesiminin bu eğitimlerden faydalanmasının sağlanması gerekmektedir.

- Pandemi sürecinin hala devam etmesi ve yüz yüze eğitimin başlaması çeşitli risk faktörlerini beraberinde getirmektedir. Kalabalık okul ortamlarının, sosyal mesafe ve hijyen kurallarını ihlal etmeye açık olması sebebiyle öğretmenlerin öğrencilere rol model olması ve gerekli koruyucu sağlı önlemlerini aktarması amacıyla sağlık okuryazarlığı açısından gelişim göstermeleri önemlidir.

\section{KAYNAKLAR}

1. T.C. Sağlık Bakanlığı Sağlığın Geliştirilmesi Genel Müdürlüğü. Ankara İli Sincan İlçesi Birinci Basamak Sağlık Personelinde Sağlık Okuryazarlı̆̆ ile İlgili Eğitim Programı Geliştirilmesi. Yayın No: 1085. Ankara: Sağlık Bakanlı̆̆ı; 2018.

2. Yılmazel G, Çetinkaya F. Sağlık okuryazarlığının toplum açısından önemi. TAF Preventive Medicine Bulletin. 2016;15(1):70-71. 
3. Paasche-Orlow MK, Wolf MS. The causal pathways linking health literacy to health outcomes. Am J Health Behav. 2007;31(1):19-S26.

4. Toçi E, Burazeri G, Kamberi H, Jerliu N, Sorensen K, Brand H. Socio-economic correlates of functional health literacy among patients of primary health care in Kosovo. Public Health. 2014;128(9):842-848.

5. Adams RJ, Appleton SL, Hill CL, Dodd M, Finlay C, Wilson DH. Risk associoated with low functional health literacy in an Australian. The Medical Journal of Australia. 2009;191(10):530-534.

6. United States Department of Health and Human Services Office of Disease Prevention and Health Promotion. National Action Plan to Improve Health Literacy. Washington, DC; 2010.

7. T.C. Sağlık Bakanlığı Sağlığın Geliştirilmesi Genel Müdürlüğü. Türkiye Sağlık Okuryazarlı̆̆ Düzeyi ve İlişkili Faktörleri Araştırılması. Yayın No: 1103. Ankara: Sağlık Bakanlığı; 2018.

8. Bilir N. Sağlık okur-yazarlığı. Turk J Public Health. 2014;(12)1:62-63.

9. Lamanauskas V. Teacher health literacy: Why does it matter? Problems of Education in the 21st Century. 2018;76(1):4-6.

10. Peterson FL, Cooper RJ, Laird JM. Enhancing teacher health literacy in school health promotion: a vision for the new millennium. $J$ Sch Health. 2001;71(4):138-144.

11. American Association for Health Education. Resolution for Teacher Preparation in Health Education. September 1996.

12. Duell N, Steinberg L. Positive risk taking in adolescence. Child Development Perspectives. 2019;13(1):48-52.

13. Şimşek Z. Sağlığı geliştirmenin tarihsel gelişimi ve örneklerle sağlı̆̆ geliştirme stratejileri. TAF Preventive Medicine Bulletin. 2013;12(3):347.

14. Deniz S, Bentli R, Kalkanlı MR, et al. Determination of Health Literacy Levels and Related Factors of Teachers Working in Malatya. Sakarya Tip Dergisi. 2020;10(1):28-36. 
15. Tonka U. Yatılı Bölge Okullarının Sorunları ve Çözüm Önerileri [Tezsiz Yüksek Lisans Projesi]. Denizli: Pamukkale Üniversitesi Eğitim Bilimleri Enstitüsü; 2018.

16. Işıkoğlu YE. Hakkâri İlinde Bulunan Yatılı İlköğretim Bölge Okullarının Olanakları ve Sorunları [Yayınlanmamış Yüksek Lisans Tezi]. Ankara: Ankara Üniversitesi Eğitim Bilimleri Enstitüsü; 2007.

17. Gökyer N. Yatılı ilköğretim bölge okullarının sorunlarına ilişkin öğrenci ve öğretmen görüşleri. Buca Eğitim Fakültesi Dergisi. 2011;30:288-310.

18. Arabacı İB. Ortaöğretim okullarında sağlık hizmetlerinin yönetici, öğretmen ve öğrenci görüşlerine göre incelenmesi. Ĕ̆itim ve Bilim. 2010;35(158):101-114.

19. Nakayama K, Osaka W, Togari T, et al. Compreshensive health literacy in Japan is lower than in Europe: a validated Japanese language assessment of health literacy. BMC Public Health. 2015;23(15):505.

20. Sveikauskas V. Peculiarities of the health literacy education system. Medicina. 2005;41(12):1061-1066.

21. Lamanauskas V, Armoniene J. Healthy lifestyle in comprehensive school: Lithuanian upper secondary school students' position. European Journal of Health and Biology Education. 2012;1(1):53-73.

22. HLS-EU CONSORTIUM (2012): Comparative report of health literacy in eight EU member states. The European health literacy survey. Online Publication: http://www.health-literacy.eu 